\title{
FROM ART TO SCIENCE OF CONSTRUCTION: THE PERMANENCE OF PROPORTIONAL RULES IN THE "STRANGE CASE" OF THE 19 CENTURY PONTE TARO BRIDGE (PARMA, ITALY)
}

\author{
F. OTTONI ${ }^{1 *}$, V. BRAGLIA ${ }^{2}$, E. COÏSSON ${ }^{2}$ AND L. FERRARI ${ }^{2}$ \\ ${ }^{1}$ Department of Engineering and Architecture (DIA) \\ Università di Parma \\ Viale Parco Area delle Scienze 181/A, 43124 Parma, Italy \\ e-mail: federica.ottoni@unipr.it,www.unipr.madlab.it (*corresponding author) \\ ${ }^{2}$ Department of Engineering and Architecture (DIA) \\ Università di Parma \\ Viale Parco Area delle Scienze 181/A, 43124 Parma, Italy \\ e-mail: luca.braglia87@gmail.com, eva.coisson@unipr.it, lia.ferrari@unipr.it,www.unipr.madlab.it
}

Keywords: Historical masonry bridge, Proportional theory, Deformations, Crack pattern

\begin{abstract}
The bridge commissioned by Maria Luigia to Eng. Antonio Cocconcelli and built between 1816 and 1821 over the Taro River (near Parma, Northern Italy), is a very important monument, both from a cultural and strategic point of view. This 20 arches masonry bridge reaches the length of nearly 600 meters and constitutes a very interesting case study, not only for the technical and structural issues related to its restoration and use (with increased traffic loads) but also for the role that geometry played in its history and stability. In this paper, a compared analysis on the historical 'proportional theory' and the constructive features of this ancient bridge is proposed with the final aim to show the importance of recovering "empiricism" in dealing with ancient monuments. Thanks to a high precision survey the realized structure has been compared to the original project, in order to detect the deformations suffered by the structure in time, thus applying the "historical monitoring" procedure to the monument. Hence, starting from the dimensional theory, a static analysis of the bridge is proposed by means of Mery's graphic method, in order to investigate the structural safety level of the original project, also considering the current load conditions. A comparison with the static results obtained by means of limit analysis, finally shows the validity of ancient proportional theory, which can constitute a first qualitative method for structural validation of ancient masonry structures.
\end{abstract}

\section{INTRODUCTION}

It is well known that 'empiricism' has been at the base of main architectural constructions up to the 17th Century, but this geometrical method of structural design has been used, in particular for bridges, at least until the beginning of the 19th Century, despite the availability of the new theories of the newborn Building Science. 
This permanence over the centuries has definitely shown that, despite the fact that the ancient master-builders didn't possess the modern mathematical instruments (proper of the modern science of construction) they have realized such complex structures, perceiving by intuition a 'static sense' which permitted them to correct the previous constructive 'errors', just by observing the past.

Not always these geometrical rules have been codified in proper architectural treatises; most of times - also etymologically - 'monuments' are 'documents' of many basic evolutions (geometrical and constructive) in the history of construction.

Each improvement or dimensional change is due to a significant technological enhancement which derives from the understanding of failures: each successful construction can be considered as the result of a 'pre-vision', adequate and complete, of what would have not worked. We can call this method 'empiricism'.

The 'error', is the vantage point for observing the evolution of masonry structures during centuries and the reconstruction of this historical route can represent an additional fundamental instrument for a deeper knowledge of these magnificent historical structures and it can help in clarifying the difficult process from 'art' to 'science' of construction [1].

This procedure can help in investigating the real present structural behavior of ancient masonry buildings and infrastructures, considering and reliably interpreting their present geometry in terms of constructive corrections or deformations occurred during time. The final aim of the work is to show the permanence of empirical analysis and proportional theory in defining reliable strategies of conservation for ancient masonry structures, thus confirming even in structural analys

\section{THE DIMENSIONAL RULES AND THE STRANGE OF BRIDGES In the 'correct' ancient constructions (and tho}
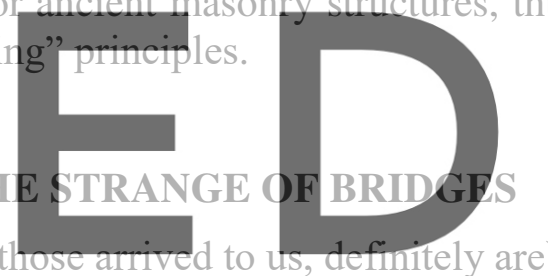
element has a proper role - from the aesthetical, static and technical point of view - matured

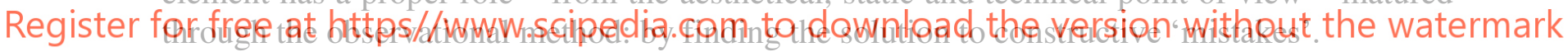

The ancient master-builders were certainly unaware of the theory at the base of the structural behavior of masoniry, which slowly developed after centuries of construction practice; nevertheless, they could experiment the final effects of this structural mechanism through the simple observation of cracks.

Despite their massive appearance, masonry structures are essentially labile, not isostatic. Still at the beginning of the 20th century, G.B. Milani, shows their peculiarity, underlying the difference with the new 'elastic systems': a monolithic structure "can remain in equilibrium for each value of $S$ for which the resultant $R$ is internal to the section" [2].

What has to be avoided is its overturning, that, regardless of resistance values, inevitably occurs when the resultant force falls outside its thickness. Then, the geometrical ratio between the thickness of the wall and its height is the fundamental parameter, in order to state the stability condition of the wall itself in front of horizontal forces (like the thrust of arches).

It is well known that there are at least three main prescriptions provided by the various treaties for a correct construction of arches [3]: the best shape (the "more solid" one); the limit thickness (the minimum possible) for that shape $(e)$, which is often provided in relation to the 
span of the arch itself (e / L); and finally the thickness of the piers (p), also very often given compared to the span ( $\mathrm{p} / \mathrm{L})$.

Only few ancient authors [4] explicitly solved the question of pier slenderness $(\mathrm{h} / \mathrm{p})$ for arches, while this fundamental data is, more often, derivable by the "architectural orders" theory. For these fundamental structures, until the 17th century few variations are recorded in the proportional rules, which see the best shape in the round arch, an ideal thickness equal to $1 / 10$ of the span and an ideal ratio between span and thickness of the piers equal to $1 / 3$, recovering the "medieval rule", also knew as "Gothic rule n.1" [5].

In time, the thickness of piers is reduced to $\mathrm{p}=\mathrm{L} / 4$, which increases in the case of the lowered arches and decreases for the acute ones, thus displaying the thrust intensity.

In this permanence, an interesting case is that of the bridges, which bring together different dimensional issues (foundations, pillar thickness, thickness and shape of the vaults, span and size of the spandrel walls), closely related to precise and particular technical-construction problems (filling, roadway materials, hydraulic and material problems).

In particular, the size of the pillars represents a central theme, having to answer both questions simultaneously: the piles of a bridge must resist the thrust of the various spans and, at the same time, must have a shape and a size which do not hinder the passage of the water between the spans, often of different sizes.

In step with this, the 'proportional theory' at the base of the main architectural treatises and buildings (from XV to XVII Century) have been herein analyzed, relatively to bridge constructive criteria and in the following Tab.1, the dimensional prescriptions for masonry bridges given by the ino

As for the treatise what will be the officia (L) of the bridge as the the rules formulated
doctrine for bridges
main reference. Acc
span $(\mathrm{e}=\mathrm{L} / 10)$ while

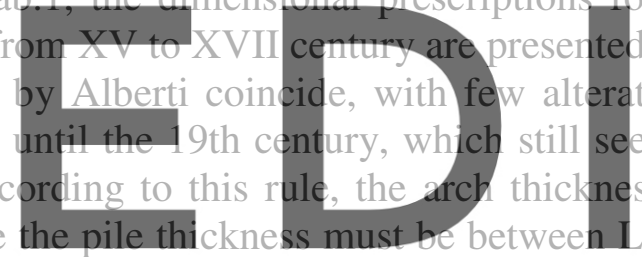
rations
IL $/ 4$ a masonry
the sprin
must be
and L/6 [6]

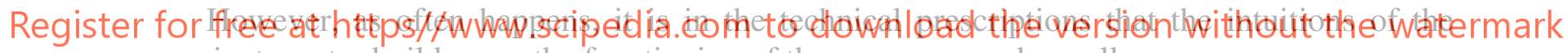
ancient master builders on the functioning of the masonry can be really seen.

Table 1: The dimensional prescriptions for bridges, on vauits $(e)$ and piles $(p)$ thickness, in comparison to their span (L).

\begin{tabular}{ccc}
\hline BRIDGE RULE & $\mathbf{e} / \mathbf{L}$ & $\mathbf{p} / \mathbf{L}$ \\
\hline Roman bridge - Rimini & $1 / 6$ & $1 / 2$ \\
\hline Medieval bridge on Bacchiglione & $1 / 10$ & $1 / 5$ \\
\hline Alberti's rules & $1 / 12$ & $1 / 4-1 / 6$ \\
\hline Palladio bridge in Vicenza (on Rerone) & $1 / 12$ & $1 / 6$ \\
\hline Palladio's bridge (treatise) & $1 / 12$ & $1 / 5$ \\
\hline Fra Lorenzo da San Nicolas rules & $1 / 10$ & $1 / 3$ \\
\hline Vincenzo Scamozzi's rules & $1 / 12$ & $1 / 4$ \\
\hline Hubert Gautier (1716) & $1 / 12$ & $1 / 6$ \\
\hline Cocconcelli's bridge in Ponte Taro & $1 / 18$ & $1 / 6$ \\
\hline
\end{tabular}

As for the best shape to be assigned to the arches, indeed, we assist to a "license" - granted only to bridges - with respect to Alberti's "doctrine of the ideal arch": the possibility of using lowered arches (if necessary) is foreseen, only on condition of strengthening the spandrel walls. In particular, Alberti insists on the need - on a technical-constructive level - to reinforce 
the filling of the vaults and to set them in the best way, using solid and large-sized blocks, especially when bridges are called to support large live loads. For these structures, indeed, the proportional rules are not simply reducible to dimensional parameters; conversely, in the technical/qualitative construction prescriptions the most interesting insights on the real behavior of masonry can be read. In this peculiar aspect - thus in the need to support not only their own dead load, but also additional, even large, ones - coupled with the hydraulic performance, we can fix the main difference between bridges and other historical vaulted masonry structures: these two combined aspects led, over time, to the maximum reduction of the pile thickness (for hydraulic efficiency) compensated by an extreme care in the construction technology used.

Therefore, only the occurrence of both aspects involved in the design of an ancient masonry bridge - thus the respect of the ancient dimensional rules and proportions, and the use of the correct technology in material arrangement and in vault construction - can constitute a reliable qualitative method for expeditious "stability analysis" of ancient bridges, thus anticipating the results of further limit analysis.

This is the case of the Ponte Taro bridge, below described, in which, on one side, the evidence of respect of proportional rules has anticipated the results of further static analysis (Mery's method and safe theorem application) showing a first guarantee of its stability, and, on the other side, the damage observed can be directly attributable to the inadherence to some technological prescriptions, which conversely are central to bridges.
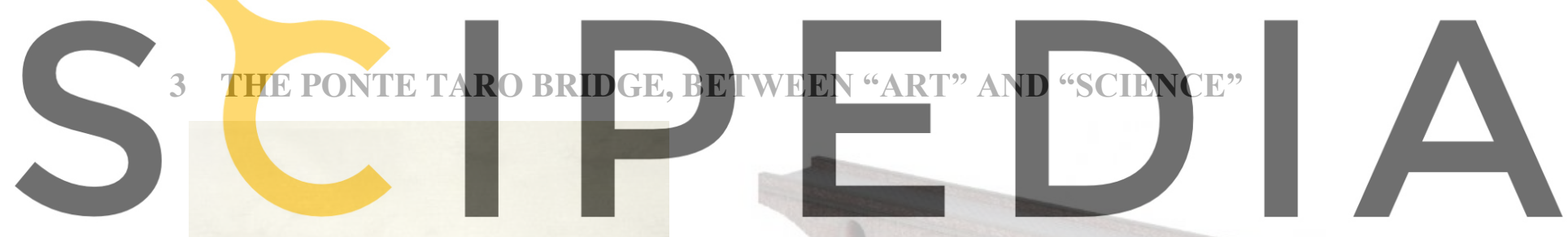

Register for free at https//www.scipedia.com to download the version without the watermark

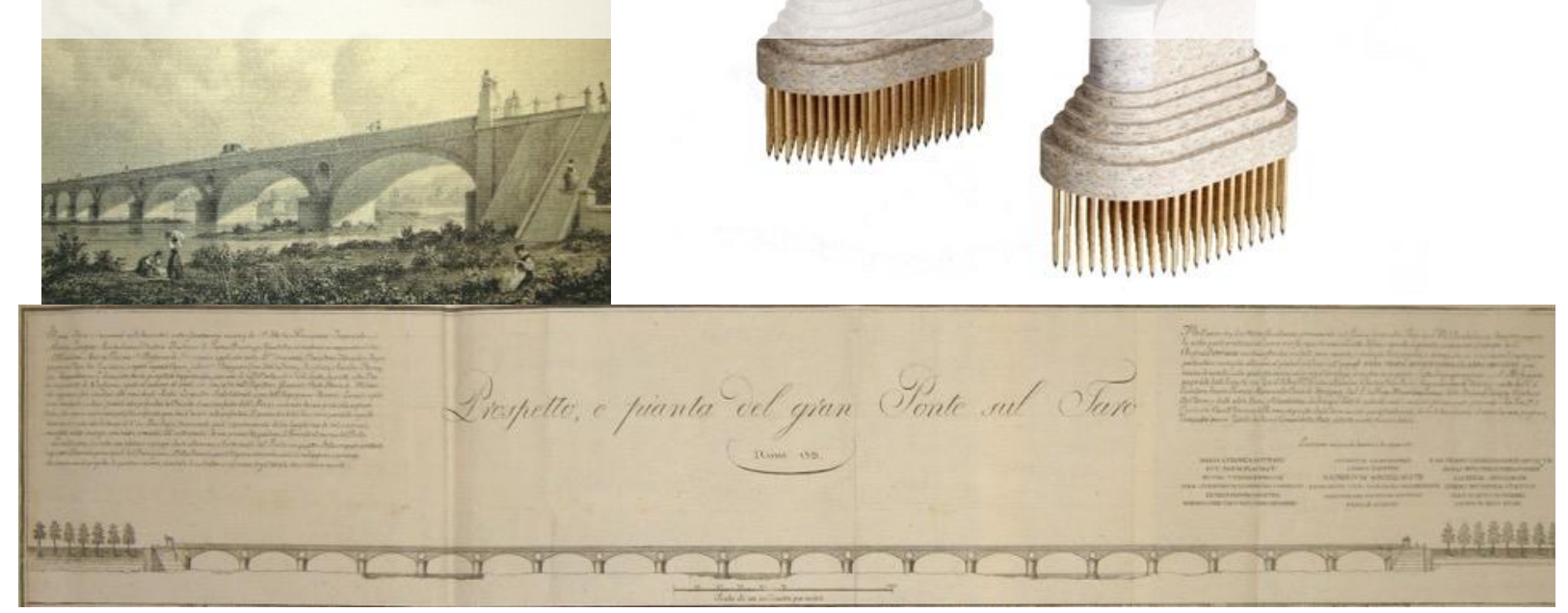

Figure 1. The Ponte Taro bridge: longitudinal prospect by Antonio Cocconcelli (below) and virtual reconstruction of the structure (above, right) 
The construction of the Ponte Taro bridge, commissioned by Maria Luigia, duchess of Parma, to Eng. Antonio Cocconcelli, took place between 1816 and 1821. After several calculations and comparison with proportional rules [7], the final shape of this important infrastructure was articulated in 17 three-centered, lowered arches, with a $24 \mathrm{~m}$ span, supported by rectangular pillars (rounded on the two to longitudinal prospects in order to reduce the water impact) laying on $5 \mathrm{~m}$ long timber poles as foundations. This first project was changed in 1818, after a flood, adding three arches and deepening the foundations. Moreover, in the final 20 arches bridge, whose external brick structure unfolds an internal filling of river cobblestones mixed with mortar, Cocconcelli inserted an oculus above each pillar, thus easing the outflow of water (Fig.1).

\subsection{Starting from the end: the bridge current state}

The bridge nowadays is still in use, although the main heavy traffic has been diverted on a larger road, which passes over the river Taro about $1 \mathrm{~km}$ North. The $19^{\text {th }}$ century bridge, indeed, is too narrow for the modern traffic requirements, not allowing a safe passage by cars, bicycles and pedestrians at the same time on the two directions. In the past, several accidents happened on the bridge and some ended up with vehicles breaking through the lateral walls, which are now rebuilt in about half their extension.

Most of the works carried out on the latest decades on the bridge regarded the upper "used" parts - including the roadbed layers and the lateral walls - and the bottom foundation
elements - to ensure their stability with regards to the water-flow actions. Conversely, they,
rarely faced the conservation problems of the masenry arches, which lay now in a poor state:
brick pieces have started falling from the barrel vaults on the underlying roads and paths and
some deformations are detectable on the original shape.
Are these detachments only due to surface material decays or can they be related also to

Are these detachments only due to surface material decays or can they be related also to
structural movements? Did the previous interventions on the piles foundations solve their

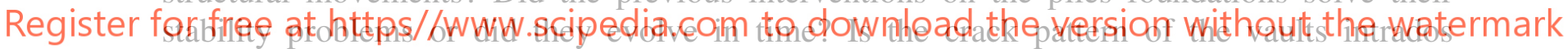
connected to constructive phases or is there a connection with the arch mechanisms?

In order to define a correct intervention approach on the bridge, and to correctly evaluate its present conditions, answering to these questions is crucial and a deep analysis of its current geometry, in comparison with the original shape, has constituted the first step in a progressive investigation path, which has mapped the decay phenomena and the crack pattern, looking for proofs on the building itself.

All the further analyses start from a reliable and detailed geometrical survey carried out in 2018 by Parma University - fully described in (Bruno et al., 2019) [8] - which used different integrated techniques: proximity range UAV photogrammetry, laser scanning and terrestrial photogrammetry with DSLR high resolution digital cameras. The over 50 TLS scans allowed to reach a Ground Sampling Distance (GSD) of about one centimeter and a resolution of the same order of magnitude of the UAV and terrestrial photogrammetric survey $(0.7 \div 1.0 \mathrm{~cm})$.

\subsection{Decay and cracks analysis}

The decay phenomena on the masonry surfaces were mapped on the photogrammetric surveys of the two façades (North and South) and of the pillars and arches, with a specific 
attention to the correct representation and quantification of the affected areas on curved shapes [8]. The analysis of the uneven distribution of these decays can supply meaningful indications about their possible origins: as predictable, the North façade is clearly more affected than the South one, due to the higher level of humidity and the consequent higher diffusion of biological patinas, black crusts and erosions. The top part of the arches is also affected by percolation of rainwater out of the roadbed: nowadays the use of de-icing salts worsens the effects of these waters on the masonry and the loss of effectiveness in time of the original drainage pipes let these waters reach the inner part of the masonry, causing diffuse efflorescence in the vaults.

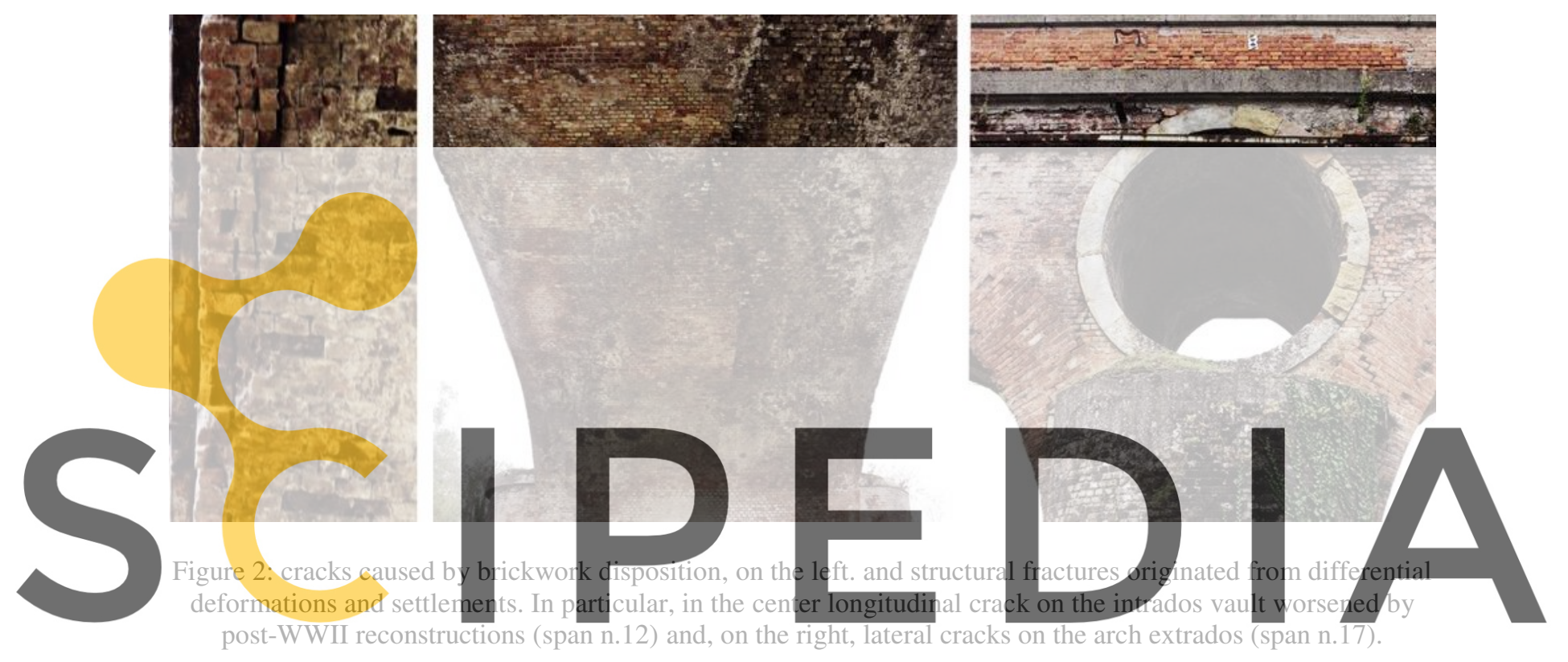

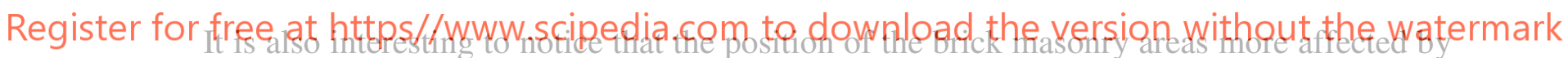

missing parts appear related to the brickwork disposition: in particular, the edge between the vauit and the arch front elevation in some cases shows the detachment of a more or less long masonry portion along the edge itself, whose boundaries seem related to the intersection between the header course masonry of the vault and of the arch, possibly also enhanced by structural stress concentrations (Fig.2, left). In some cases, the masonry portions are still in place, but already detached by a characteristic crack pattern at about $20 \mathrm{~cm}$ from the edges. Other cracks are clearly related to reconstructions, carried out after bombs hit the structure in World War II and after car accidents damaged the lateral walls.

Nevertheless, some other cracks in specific parts of the bridge can have a structural origin. These can be schematically divided in two typologies: cracks on the fronts, related to the arch mechanisms and cracks under the vaults, related to differential deformations. In the vaults n.2, n.5 and n.12, starting from the West end, longitudinal cracks are visible: these could be connected to different settlements of the North and South arches, possibly already during the removal of the centering in the building phase, as reported in some historical documents.

On the fronts, several arches show cracks on the extrados, laterally, in positions that are typical for depressed three-centered arches. When movements of the imposts (for settlements 
or rotations) are present, the crack pattern loses its symmetry. In some cases, also the parapet shows inclined cracks, related to the settlement of the arches and of the supporting piers. Both for the piers and arches settlements, for a confirmation of these hypotheses it is important to check the actual present geometry, thanks to the precise survey, identifying deformations and loss of horizontality in the two directions.

\subsection{Deformations analysis}

In order to identify the deformations, the geometrical survey has been analyzed comparing the levels of the pillars and the levels of the arches crowns, in the hypothesis that they were all (respectively) at the same level and that all the arches had the same geometry. Another basic hypothesis is that no elements increased their level in time. Therefore, comparing the levels of the elements originally aligned it was possible to identify the differential settlements both longitudinally and transversally to the bridge.

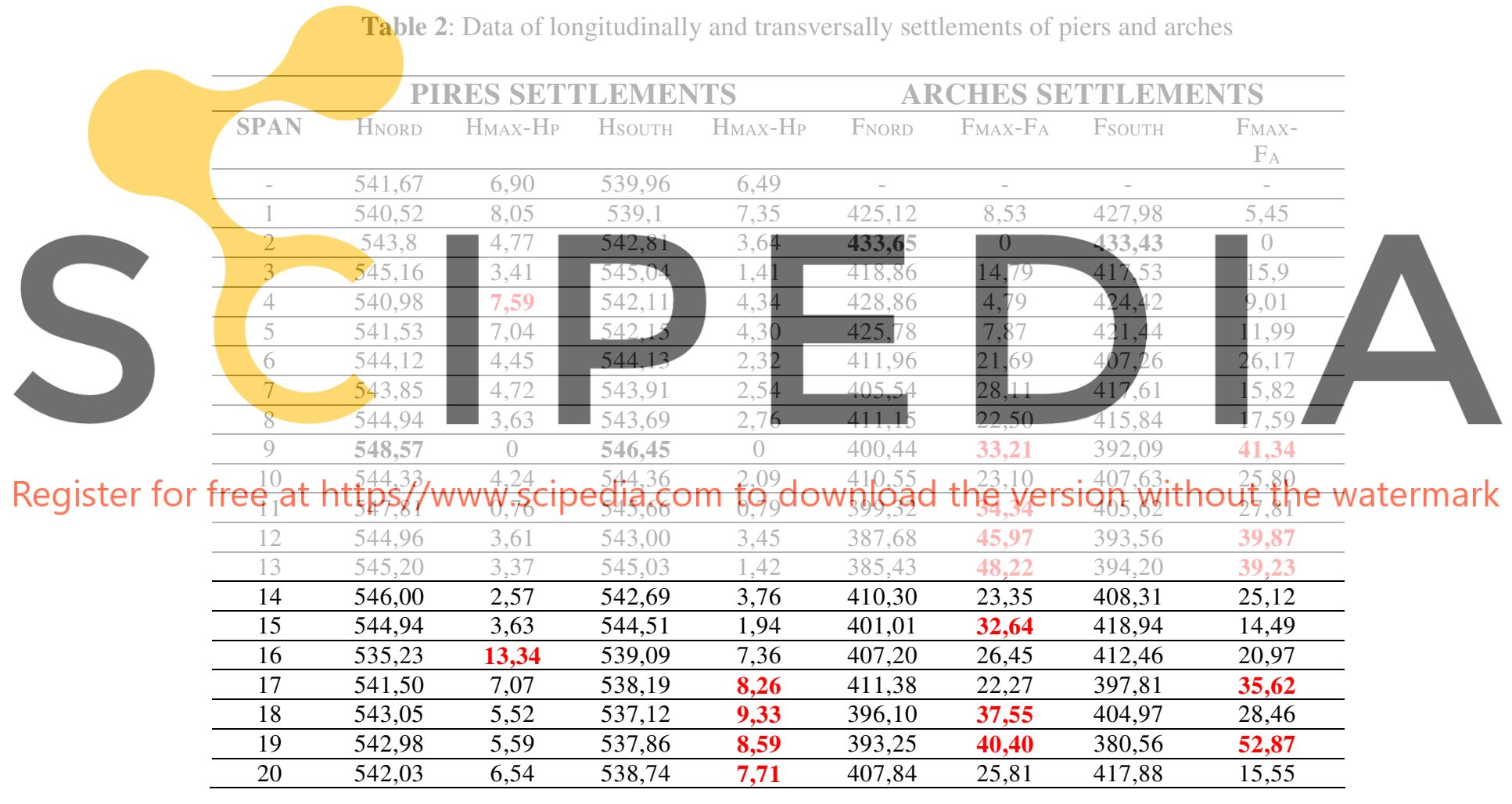

The first analysis regarded the pier top levels (Tab.2). The differential settlements turned out to be quite limited: less than $10 \mathrm{~cm}$ on more than $600 \mathrm{~m}$ of length and never more than 6 $\mathrm{cm}$ among two subsequent piers. These data prove the effectiveness of the underpinning interventions of the central piers foundations (from n.4 to n.14, starting from the West end): although these pillars are more directly affected by the river water flow, they show a mean settlement of $2.9 \mathrm{~cm}$ compared to $9 \mathrm{~cm}$ in the West piers (1 to 5) and $5.4 \mathrm{~cm}$ in the five more eastern piers. Indeed, also the geological tests had identified thicker layers of deformable silty sands on the West side while, on the East side, the stiffer gravels reach $17 \mathrm{~m}$ of depth. 
Comparing these levels on the two fronts, the differences are quite small: the maximum inclination is $6 \mathrm{~cm}$ Southwards (i.e. upstream), on the Eastern piles.

As far as the shape of the arch is concerned - and particularly its rise - a comparison was made between the survey and the design shape, as inferred by the descriptions and drawings of Cocconcelli (Fig.3, left).
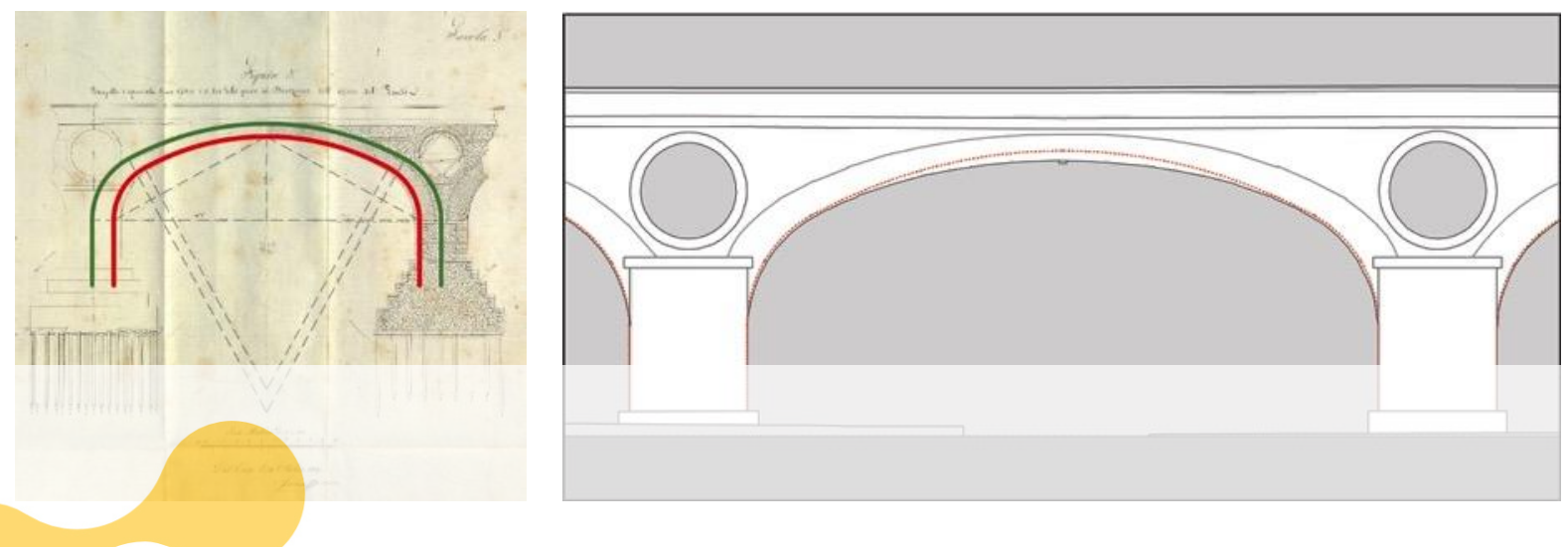

Figure 3: Differences of geometry between the original drawing by Cocconcelli (on the left) and the surveyed one (on the right, arch n.12).

7 out of 20 arches sto value seems to be inp arches during the center range between 16 and could be connected to South arch of each sp an were compared.
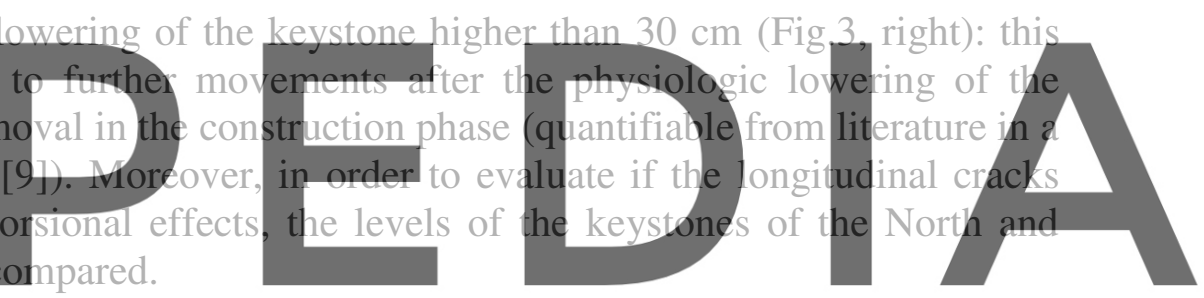

Register for free at https//www.scipedia.com to download the version without the watermark
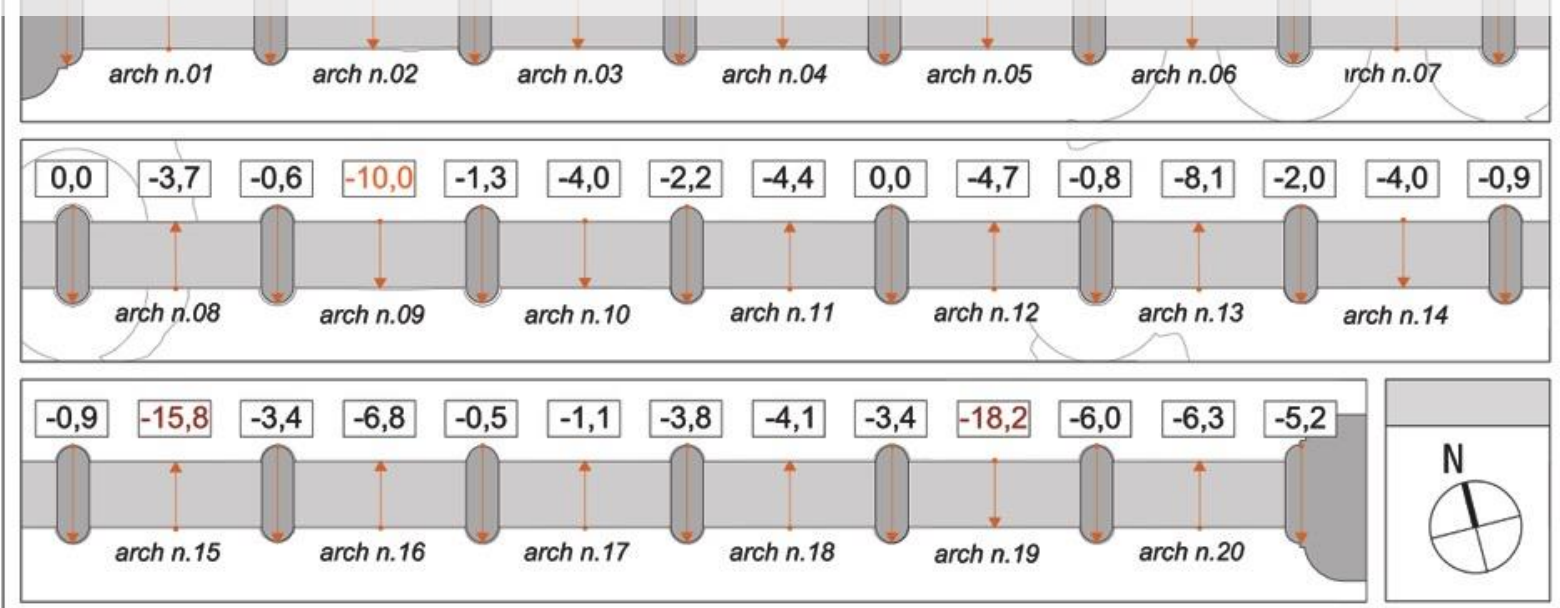

Figure 4: Comparison between the levels of keystones in the northern and southern side for each arch. 
From the Figure 4 it's possible to see that the highest differences - between 15 and $20 \mathrm{~cm}$ were measured in the arches $n .19(-18.2 \mathrm{~cm})$ and $n .15(-15.8)$ while the arches $n .7$ and $n .9$ show differences between 10 and $15 \mathrm{~cm}$. It is noteworthy that these level differences are not always in the same direction; anyway we can state that most of these inclinations are Southwards in the West Side of the bridge, changing Northwards in the East side (as represented by the arrows in Fig.4).

In conclusion, comparing the crack pattern with the deformation analysis, only in two arches it is possible to find correlations between the longitudinal cracks in the vault and the lowering of the keystone (n.12), as well as between the cracks in the extrados (arch n.9) and the settlement of the vault itself. This fact, together with the evidence of some loss in masonry apparatus and considering the possible mistakes during the construction phase (particularly important in the case of bridges with independent arches [10], as the case of study, Fig.5) leads to speculate that the cause of the damage is not structural but more reliably linked to local mechanisms ascribable to as many construction defects: only in these cases indeed, the question of resistance (otherwise not influential for the massive historic masonry constructions [11]) intervenes, showing local cracks.

\section{PONTS A ARCEAUX INDEPENDANTS}

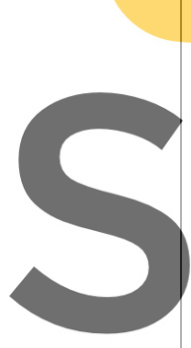

Mode de construction des arcs
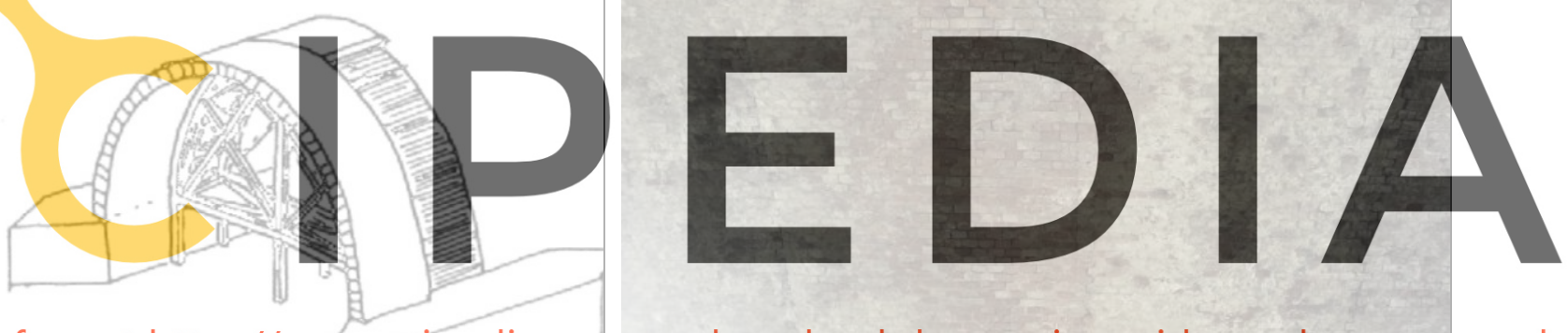

Register for free at https//WWw.Scipedia.com to download the version without the watermark

Figure 5: The longitudinal cracks below the arcades, imputable to as many mistakes in masonry apparatus during the construction phase (and the centering removal).

\subsection{The simplified static analysis: back to geometry}

In this geometrical route, an integrated analysis of the historical 'proportional theory' and the constructive characteristics of this peculiar masonry bridge has been carried out, in order to verify its stability, by a simplified and qualitative approach.

Many studies exist in literature on structural calculation of masonry bridges, which have included different load cases by using analytical and experimental methods $[12,13]$.

In this case, the first "verification" has been the adherence of the dimensions of the bridge to the prescribed proportional rules recalled in the first part of this paper (Fig.6, left).

By analyzing the main dimensions of the span and the pillars, indeed, it can be seen that the prescribed ratio of $\mathrm{p} / \mathrm{L}$ equal to $1 / 6$ is verified, thus following the proportional method, as explicitly declared by Antonio Cocconcelli himself in his project [7]. 
What we can notice is a slight "licence" in the thickness of the arches: Cocconcelli applied in his bridge a smaller ratio than the one prescribed by treatises, reaching - in the keystone - a thickness equal to L/18. This advancement certainly derived from the Mery's method results, used during his calculations of the bridge, whose reliability is definitely confirmed by the evidence that, despite the load over the bridge has significantly increased in time (up to the current traffic), it has demonstrated, until now, a surprisingly high load bearing capacity.

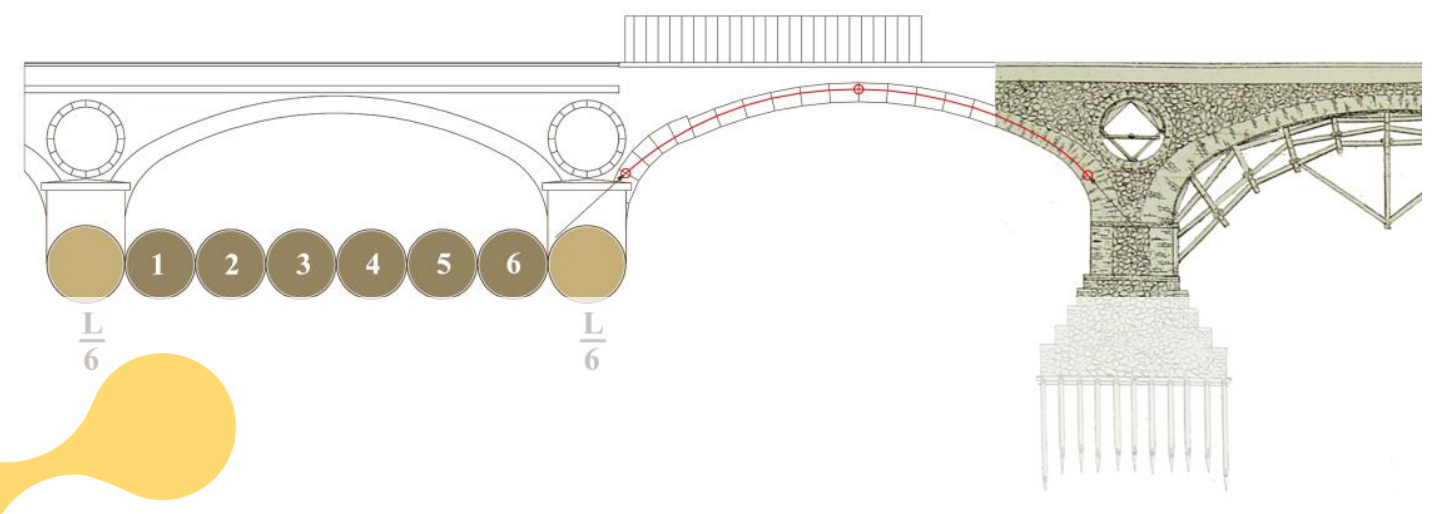

Figure 6: From the left, the analysis of the bridge: starting from the proportional theory to the "safe theorem" with the current loads.

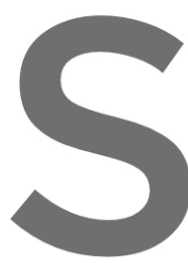

Therefore, recoverin dimensioning of its bric analysis (fig.7, left), abutments, constituted of river cobblestones mi
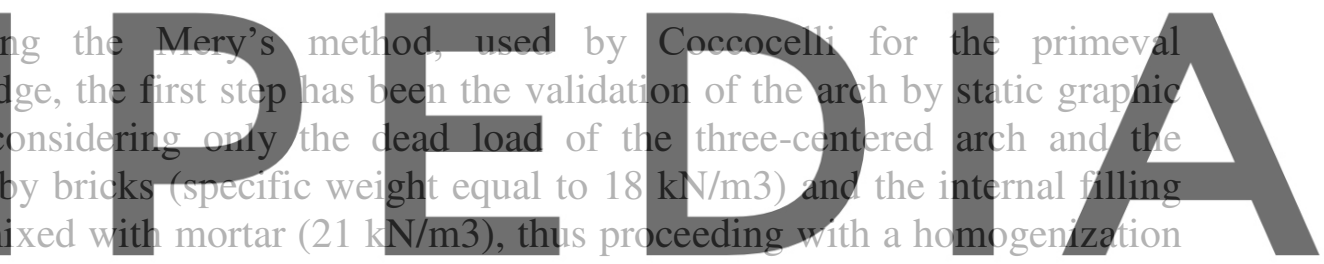

of the blocks. From this simple analysis, the curve of pressure was found to be all contained

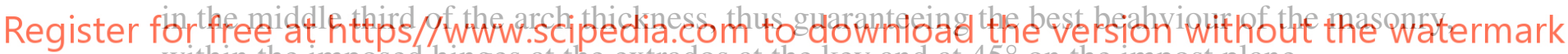
within the imposed hinges at the extrados at the key and at $45^{\circ}$ on the impost plane.

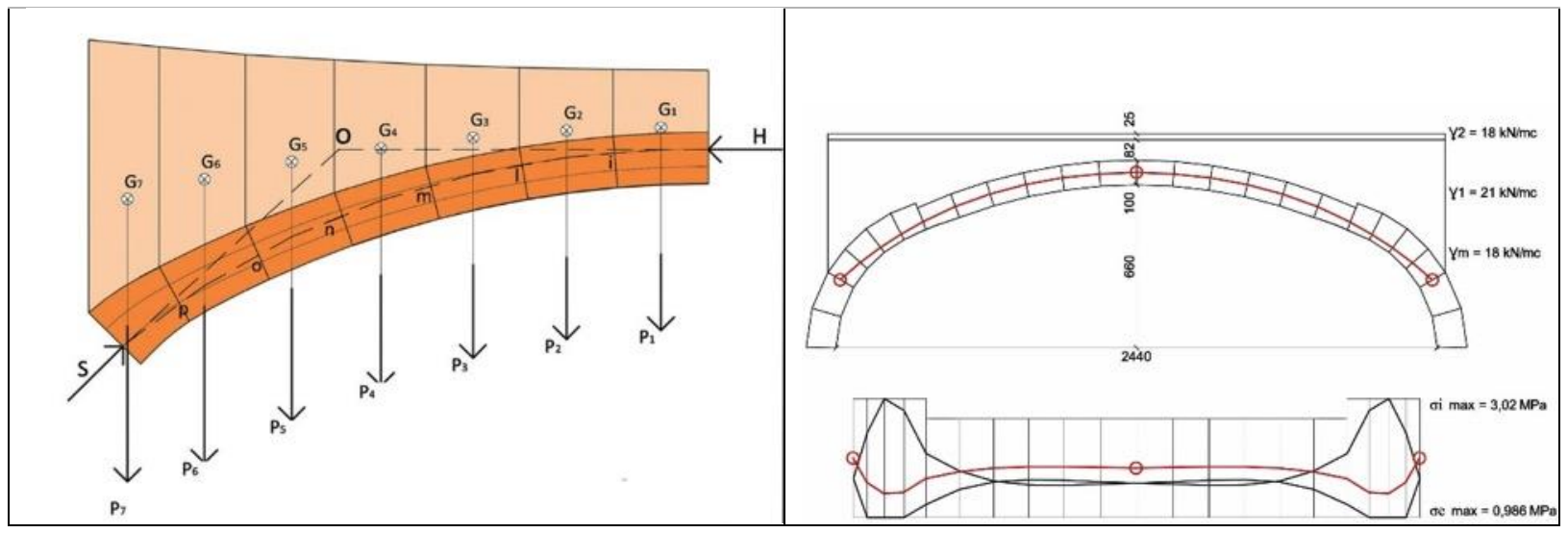

Figure 7: On the left, the result of the pressure curve with Mery's static analysis method, applied to the arch subject to dead load (with filling). On the right the same condition analyzed by limit analysis method. 
The same result has been obtained by applying simplified limit analysis to the complete arch, considering the abutments and the different thickness at the imposts $(1,30 \mathrm{~m}$ in the key and $1,6 \mathrm{~m}$ at the abutments).

The "safety factor" obtained in this case (intended as a ratio between the thickness of the arch and the minimum one suitable to contain the pressure curve) was 3,88 , thus well above the collapse limit stated by Heyman [14].

As well known by literature and observed in the built evidences, the load on the abutments improves the stability of the structure: indeed, the same analysis carried out on the arch itself, without this additional load (Fig.8, left), restituted a sensibly lower "safety factor" $(2,54)$, however far above the minimum required for stability.

Surprisingly, even the simulation of the current worse load combination has given good results: the third simulation saw the load of a 5-axle articulated lorry $(17 \mathrm{kN} / \mathrm{m})$ in the worst, asymmetrical, configuration on the arch. Also for this extreme condition, the limit analysis of the arch, even simplified, has shown a sufficient "safety factor" $(2,22)$.

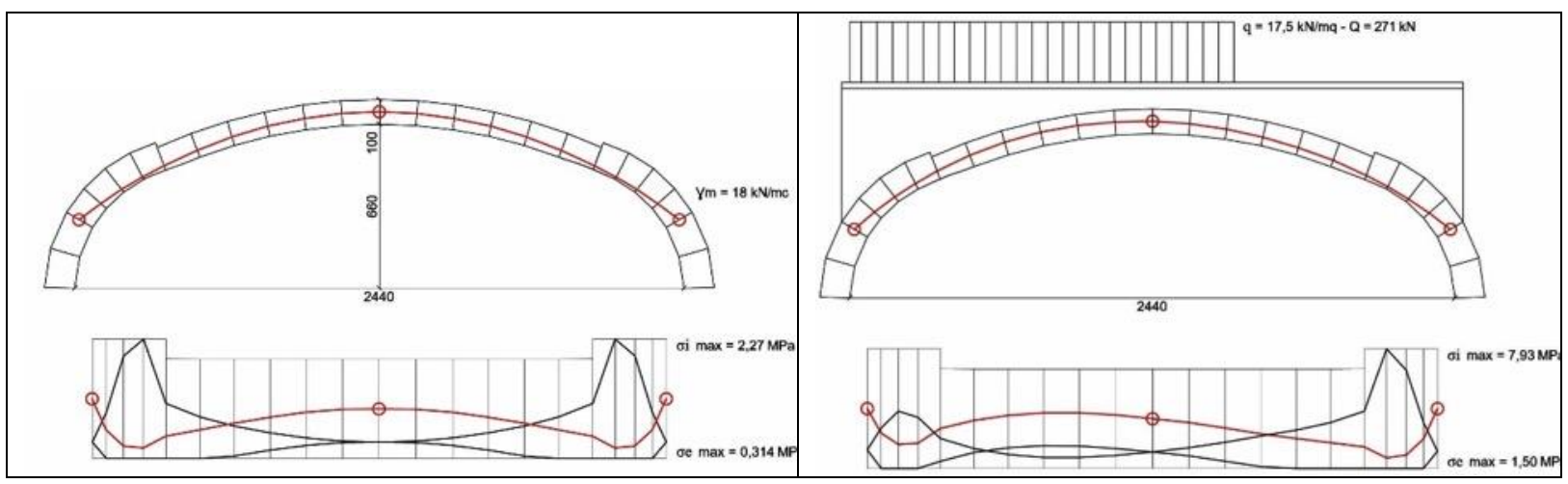

Figure 8: The results of limit analyses of the arch in the simple configuration (with the only dead load, without abutments) and in the current load conditions (on the right).

\section{CONCLUSIONS}

The history of construction can be ultimately seen as the translation of structure into geometry: the final shape of a construction used to be the formal result of an empiric calculation - strict and scientific: each built monument constitutes an experiment, 1:1 scale, whose positive, or even more negative outcomes (as repeated collapses) has given in time important pieces of information for the correction of the 'mistakes'.

The comparison between similar mechanisms and pathologies has allowed to trace the field of application of these theories in solving the safety problem and in guaranteeing the equilibrium of masses.

In step with this, the information obtainable through a specific interpretation of the geometrical survey data can represent powerful tools for the comprehension of the present structural conditions of an historical structure and precious elements for the validation of any further numerical model [15]. Moreover, retracing in the structure, the ancient dimensional rules prescribed for the specific building typology, can constitute a first and expeditious method of analysis which, recovering the equilibrium principles, can give a reliable base for further and more complex analyses, which are not always gobernable in the final results. 
Recovering the principles (dimensional and technical) which governed the design and the construction of ancient structures, is the first step to reliably interpret, even in a very simplified way, their current damage and residual behavior, which is the first condition for setting up a correct strategy of structural strengthening.

\section{REFERENCES}

[1] J. Heyman, Structural Analysis: an historical approach, Cambridge University Press, Cambridge, 1998.

[2] G.B. Milani, L'ossatura murale, Crudo \& C., Turin, Italy, 1920.

[3] S. Huerta, Arcos, bovedas y cupolas: Geometria y equilibrio en el calculo tradicional de estructuras de fabrica, Tapa Blanda, 2004

[4] S. Sanabria, The mechanization of design in the 16th century: The structural formulae of Rodrigo Gil de Hontañon, Journal of the Society of Architectural Historians, 41, 1981, pp. 281-293

[5] F. Blondel, Cours d'architecture enseigné dans l'Académie Royale d'Architecture, Paris, 1675, parts II-V

[6] E.M. Gauthey, Traité de la construction des ponts, Firmin Didot, Paris 1809

[7] A. Cocconcelli, Descrizione dei progetti e lavori per l'innalzamento dei due ponti sul Taro e sulla Trebbia, Parma, 1825

[8] N. Bruno, E. Coïsson, F. Diotri, L. Ferrari, S. Mikolajewska, U. Morra di Cella, R. Roncella, A. Zerbi, History, geometry, structure: interdisciplinary analysis of a historical bridge. ISPRS Annals of the Photogrammetry, Remote Sensing and Spatial Information Sciences, 2019, Vol XLII-2/W11, pp.317-323.

[9] F. Derand, L'Architecture des voûtes, ou l'Art des traits et coupe des voûtes... par le R.P. François Derand, Sebastian Cramoisy, Paris 1643

[10] J. Mesqui, Chateaux at encentes de la France médiévale: de la défense à la résidence, Editions A\&J Picard, Paris, 2013

[11] S. Huerta, Galileo was wrong: the Geometrical design of masonry arches, Nexus Network Journal, 8, 2006, 2, pp. 25-52

[12] A. Brencich, D. Sabia, Experimental identification of a multi-span masonry bridge: The Tanaro Bridge, Constr. Build. Mater., 22, 2008, pp.2087-2099

[13] D.V. Oliveira, P.B. Lourenco and C. Lemos, Geometric issues and ultimate load capacity of masonry arch bridges form the northwest Iberian Peninsula, Eng. Struct., 32, 2010, pp. 381-394.

[14] J. Heyman, The Masonry Arch, Ellis Horwood, Chichester, 1982.

[15] S. Huerta S. Mechanics of masonry vaults: The equilibrium approach, Historical Constructions, PB Lourenço, P Roca (Eds.), Guimarães, 2001. 